\title{
The impact of panitumumab treatment on survival and quality of life in patients with RAS wild-type metastatic colorectal cancer
}

This article was published in the following Dove Press journal: Cancer Management and Research

\author{
Francesca Battaglin' \\ Alberto Puccini ${ }^{2}$ \\ Selma Ahcene Djaballah ${ }^{3}$ \\ Heinz-Josef Lenz' \\ 'Division of Medical Oncology, Norris \\ Comprehensive Cancer Center, Keck \\ School of Medicine, University of \\ Southern California, Los Angeles, CA \\ 90033, USA; ${ }^{2}$ Medical Oncology Unit I, \\ IRCCS Ospedale Policlinico San Martino, \\ Genova, Italy; ${ }^{3}$ Medical Oncology Unit I, \\ Clinical and Experimental Oncology \\ Department, Veneto Institute of \\ Oncology IOV - IRCCS, Padua 35I28, \\ Italy
}

Correspondence: Heinz-Josef Lenz Division of Medical Oncology, Norris Comprehensive Cancer Center, Keck School of Medicine, University of Southern California, I44I Eastlake Avenue, Suite 3456, Los Angeles, CA 90033, USA

Tel +l 3238653967

Email lenz@med.usc.edu

\begin{abstract}
Panitumumab is a fully human monoclonal antibody targeting the epidermal growth factor receptor (EGFR). It is currently approved for the treatment of $R A S$ wild-type (WT) metastatic colorectal cancer (mCRC) in combination with chemotherapy in first- and second-line and as monotherapy in chemorefractory patients. This review will provide an overview of main efficacy data on panitumumab from its early development up to latest evidences, including novel perspectives on predictive biomarkers of anti-EGFRs efficacy and mechanisms of secondary resistance. Quality of life (QoL) related issues and panitumumab safety profile will be addressed as well.
\end{abstract}

Keywords: panitumumab, colorectal cancer, EGFR, RAS, biomarker, quality of life

\section{Introduction}

Colorectal cancer (CRC) is the third most frequently diagnosed malignancy both in men and in women and represents one of the leading causes of cancer-related mortality worldwide. ${ }^{1}$ In recent years, an extended molecular characterization of CRC has led to a deeper understanding of the mechanisms of development and heterogeneity of this disease. Novel targeted agents including vascular endothelial growth factors (VEGF)-, epidermal growth factor receptor (EGFR)- and more recently immune checkpoints-inhibitors have become available for the treatment of mCRC, adding to standard chemotherapy with 5-fluorouracil, oxaliplatin and irinotecan. ${ }^{2}$ The improvement in medical treatments, together with enhanced locoregional and surgical approaches, has translated into a longer median overall survival (OS) of patients with mCRC which has surpassed 30 months in modern day practice. $^{3}$

The EGFR signaling pathway plays a critical role in CRC development and EGFR inhibitors are well established therapeutic agents in mCRC treatment. Panitumumab is a fully human monoclonal antibody (mAb) which targets with high affinity the extracellular domain of EGFR, competitively inhibiting the binding of other ligands and thus preventing the activation of the EGFR downstream signaling cascade (Figure 1). ${ }^{4}$ In malignant cells the activation of EGFR promotes cell proliferation through the KRAS/RAF/MAPK and the PI3K/AKT/mTOR axes. ${ }^{5}$ EGFR blockade by panitumumab results in inhibition of cell growth, induction of apoptosis, decreased of proinflammatory cytokines and VEGF production, and EGFR downregulation through receptor internalization. ${ }^{6,7}$ Over time, the clinical 


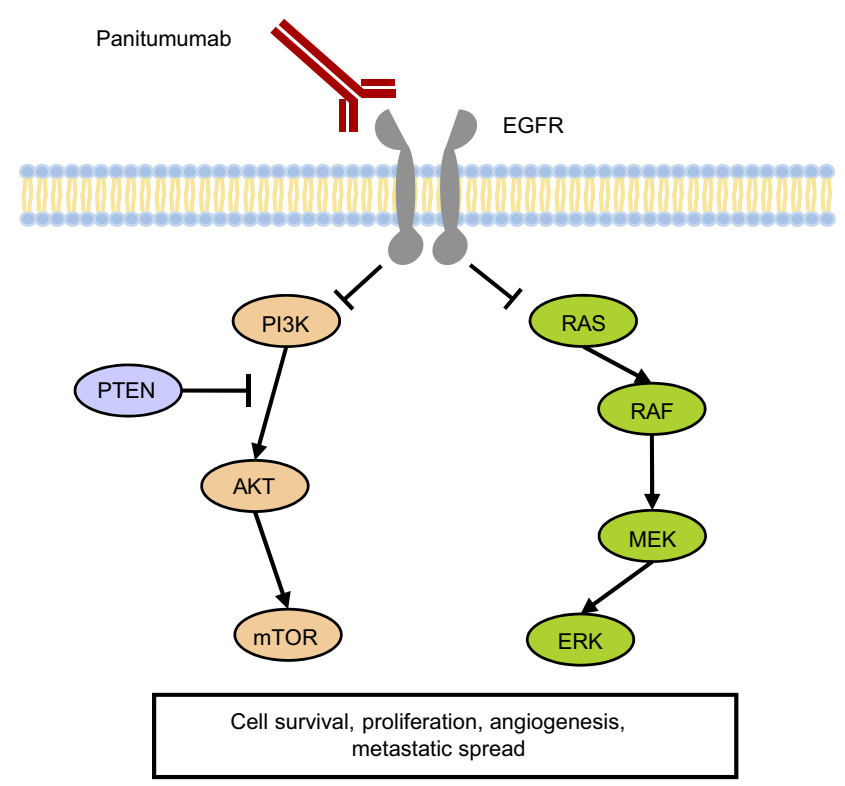

Figure I Panitumumab, a fully humanized monoclonal lgG2 antibody, inhibits the EGFR pathway.

Abbreviations: AKT, AKT8 virus oncogene cellular homolog; EGFR, epidermal growth factor receptor; ERK, extracellular signal-regulated kinase; MEK, mitogenactivated protein kinase kinase; mTOR, mammalian target of rapamycin; PI3K, phosphatidyilinositol 3-kinase; PTEN, phosphatase and tensin homolog; RAF, v-Raf murine sarcoma viral oncogene homolog; RAS, rat sarcoma viral oncogene homolog.

efficacy of panitumumab in $\mathrm{mCRC}$ has been proven by several randomized trials across different treatment lines, however since early studies it was clear that not all patients benefit from this treatment. Hence, the identification of predictive biomarkers has been paramount in panitumumab studies, paving the way to the discovery of rat sarcoma $(R A S)$ mutations as negative predictive biomarkers for anti-EGFRs activity. ${ }^{8}$

In this review, we will provide an overview of panitumumab activity across different treatment scenarios and treatment lines in mCRC. We will also address the impact of panitumumab treatment on patients' quality of life (QoL) and discuss novel perspectives on patient selection and primary and secondary resistance mechanisms to antiEGFR agents.

\section{Regulatory approval and molecular patient selection}

Panitumumab is currently approved by the Food and Drug Administration (FDA) and European Medicines Agency (EMA) for the treatment of $R A S$ wild-type (WT) mCRC in combination with FOLFOX (5-fluorouracil, leucovorin and oxaliplatin) or FOLFIRI (5-fluorouracil, leucovorin and irinotecan) in the first-line setting; in combination with FOLFIRI in the second-line setting; and as monotherapy following disease progression after prior chemotherapy treatment (fluoropyrimidine-, oxaliplatin- and irinotecan-containing regimens). ${ }^{4}$

Regulatory Agencies have also provided recommendations on validated laboratory techniques and accreditation criteria for $R A S$ mutation testing, which should be performed only in highly qualified and certified laboratories. In 2017, the American Society of Clinical Oncology (ASCO) in collaboration with the Association for Molecular Pathology, the College of American Pathologists, and the American Society for Clinical Pathology, published a set of dedicated guidelines on the evaluation of molecular biomarkers in CRC. ${ }^{9}$ According to the current standard of practice every patient being considered for anti-EGFR treatment must receive $R A S$ mutational testing and the analysis should include $K R A S$ and $N R A S$ codons 12, 13 of exon 2; 59, 61 of exon 3; and 117 and 146 of exon $4 .^{8}$

More recently, several other tumor molecular features and mutations in genes involved in EGFR-related pathways have been shown to play a role in anti-EGFRs resistance mechanisms. The $V$-Raf murine sarcoma viral oncogene homolog B1 (BRAF) V600E mutation is one of these, and growing evidence supports the use of $B R A F$ as a negative predictive biomarker in clinical practice. An overview of novel biomarkers of primary and acquired resistance mechanisms is provided in the next sections.

\section{Clinical efficacy}

\section{Panitumumab monotherapy}

The open label phase III 408 trial was the first study to demonstrate a progression-free survival (PFS) benefit, although small, with single agent panitumumab compared to best supportive care (BSC) in unselected pre-treated mCRC ( 8 versus 7.3 weeks, hazard ratio (HR) $0.54 ; 95 \%$ confidence interval $(\mathrm{CI}), 0.44-0.66 ; P<0.0001) .{ }^{10}$ Later on, a retrospective biomarker analysis from this study shed light on the predictive role of KRAS exon 2 mutation on panitumumab efficacy, demonstrating a clear improvement in PFS for patients with WT tumors (12.3 versus 7.3 weeks, HR $0.45 ; 95 \%$ CI, 0.34-0.59; $P<0.0001$ ), while no benefit was observed in patients with mutated tumors (PFS 7.4 versus 7.3 weeks for panitumumab versus BSC, HR 0.99; 95\% CI, 0.73-1.36). ${ }^{11}$ These findings opened a new era for biomarker discovery and molecular patient selection, leading the restriction of the use of anti-EGFR agents to KRAS exon 2 (codon 12 and 13) WT tumors in 2008. 
The activity of panitumumab monotherapy has been compared to that of cetuximab, the first approved antiEGFR agent, in an open-label randomized phase III trial in patients with chemotherapy-refractory $K R A S$ exon 2 WT mCRC. ${ }^{12}$ Panitumumab was non-inferior to cetuximab in terms of OS, PFS, and objective response rate (ORR), with reported OS of 10.4 months and 10 months, respectively (HR $0.97,95 \%$ CI $0.84-1.11, P=0.0007$ ).

\section{Combination therapy}

Shortly after the 408 study, several trials evaluated the efficacy of panitumumab in association with chemotherapy doublets, showing significant benefit from the addition of panitumumab compared to chemotherapy alone in KRAS exon 2 WT patients, both in first- and in second-line settings (efficacy data of main trials are summarized in Table 1).

The phase III randomized 181 trial compared secondline treatment with panitumumab-FOLFIRI to FOLFIRI alone. ${ }^{13}$ The study was later amended to prospectively evaluate $K R A S$ exon 2 status as a predictor of panitumumab efficacy. In the KRAS WT population, a significant improvement in PFS was observed when panitumumab was added to chemotherapy (median PFS 5.9 versus 3.9 months, HR 0.73; 95\% CI, 0.59-0.90; $P=0.004)$; response rate was also improved to $35 \%$ versus $10 \%$ by the addition of panitumumab. A non-significant trend toward increased OS was observed for the panitumumab arm: median OS 14.5 versus 12.5 months, HR $0.85,95 \%$ CI, $0.70-1.04 ; P=0.12$. Conversely, no benefit was observed in patients whose tumors harbored a KRAS mutation. ${ }^{14}$

In the first-line setting, the phase III randomized PRIME study demonstrated the benefit of combining panitumumab with FOLFOX-4 compared to FOLFOX-4 alone in $K R A S$ exon 2 WT mCRC. ${ }^{15,16}$ Further efficacy analysis of this study, based on a more extensive patient molecular selection after the emerging evidence on the role of rare $R A S$ activating mutations (KRAS exon 3 and 4, NRAS exon 2, 3 and 4) and $B R A F$ mutations in anti-EGFRs resistance, ${ }^{17}$ proved for the first time a striking advantage from panitumumab treatment in the extended $R A S$ WT population and lack of efficacy in $R A S$-mutated tumors. Notably, in $446 R A S / B R A F$ WT patients, panitumumab was shown to confer a greater magnitude of OS benefit compared to KRAS exon $2 \mathrm{WT}$, with an impressive 7.4 months improvement over chemotherapy alone (28.3 versus 20.9 months, HR 0.74 ; 95\% CI, 0.57-0.96;
$P=0.02) .{ }^{18}$ The presence of a $B R A F$ mutation was also confirmed as an independent negative prognostic factor both for PFS and OS, irrespective of treatment.

Similar results were obtained from updated molecular analyses of randomized first-,${ }^{19}$ second- ${ }^{14}$ and third-line ${ }^{20}$ trials. A meta-analysis also confirmed the presence of extended $R A S$ mutations as negative predictive biomarkers for anti-EGFRs activity in mCRC, with no difference between $K R A S$ exon 2 mutations and other KRAS or NRAS mutations. ${ }^{21}$ These data led to the FDA restriction for the use of panitumumab to extended KRAS and NRAS WT mCRC. More recently, evidence on the role of $B R A F \mathrm{~V} 600 \mathrm{E}$ mutation as a biomarker of resistance to anti-EGFR agents has been confirmed by large meta-analyses showing a lack of treatment benefit from anti-EGFR mAbs, both in terms of PFS and OS, for BRAF-mutated mCRC. $^{22-24}$

Both anti-EGFRs and anti-VEGF agents are approved for the first-line treatment of RAS WT mCRC in association with chemotherapy and have recently been compared in different head-to-head randomized trials. The phase II PEAK study investigated the addition of panitumumab versus bevacizumab to FOLFOX chemotherapy in the first-line setting. ${ }^{25}$ Although not designed to prove the superiority of one treatment over the other, this study showed a significant improvement in PFS (13.1 versus 10.1 months, HR $0.61 ; 95 \%$ CI, 0.42-0.88; $P=0.0075$ ), and a trend towards OS (41.3 versus 28.9 months, HR $0.70 ; 95 \% \mathrm{CI}, 0.48-1.04 ; P=0.08)$ from panitumumab versus bevacizumab in the extended $R A S / B R A F$ WT population, suggesting a survival benefit from first-line use of panitumumab in association to chemotherapy in these patients. ${ }^{26} \mathrm{~A}$ recent exploratory pooled analysis evaluating the effect of sequence of biological therapies on OS in patients with $R A S$ or $R A S / B R A F$ WT mCRC treated with panitumumab across the PRIME, PEAK and 181 trials, confirmed a trend towards improved OS for first-line panitumumab plus chemotherapy followed by second-line VEGF inhibitors, compared with first-line bevacizumab followed by second-line anti-EGFRs. ${ }^{27}$ Large prospective randomized trials are warranted to further evaluate the optimal first-/second-line targeted treatment sequence in RAS WT mCRC. Of interest, the ongoing CRSEQUENCE trial from the Spanish Cooperative Group for the Treatment of Digestive Tumors (TTD), evaluating the efficacy of FOLFOX plus panitumumab followed by FOLFIRI plus bevacizumab (Sequence 1) versus FOLFOX plus bevacizumab followed by FOLFIRI plus 
Table I Efficacy results from main panitumumab trials

\begin{tabular}{|c|c|c|c|c|c|c|c|c|c|}
\hline \multirow{2}{*}{$\begin{array}{l}\text { Trial (phase) } \\
\text { Ref }\end{array}$} & \multirow{2}{*}{$\begin{array}{l}\text { Treatment } \\
\text { Arms (n.) }\end{array}$} & \multirow{2}{*}{$\begin{array}{l}\text { Treatment } \\
\text { Line }\end{array}$} & \multirow{2}{*}{$\begin{array}{l}\text { Primary } \\
\text { Endpoint }\end{array}$} & \multicolumn{2}{|l|}{ ORR (\%) } & \multicolumn{2}{|l|}{ PFS } & \multicolumn{2}{|l|}{ OS } \\
\hline & & & & $\begin{array}{l}\text { KRAS ex } \\
2 \mathrm{WT}\end{array}$ & RAS WT & $\begin{array}{l}\text { KRAS ex } \\
2 \mathrm{WT}\end{array}$ & RAS WT & $\begin{array}{l}\text { KRAS ex } \\
2 \mathrm{WT}\end{array}$ & RAS WT \\
\hline $\begin{array}{l}408 \text { (III) } \\
\text { NCT00I I } 3763 \\
10,11,20\end{array}$ & $\begin{array}{l}\text { Panitumumab } \\
\text { (n.23I) } \\
\text { BSC (n.232) }\end{array}$ & $3 r d /+$ & PFS & $\begin{array}{l}17 \% \\
0 \%\end{array}$ & $\begin{array}{l}17 \% \\
0 \%\end{array}$ & 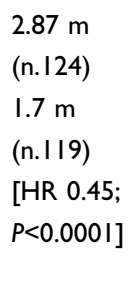 & $\begin{array}{l}\text { HR 0.39; } \\
95 \% \mathrm{Cl} \\
0.27-0.56 ; \\
P<0.001\end{array}$ & $\begin{array}{l}8.1 \mathrm{~m} \\
(\mathrm{n} .124) \\
7.6 \mathrm{~m} \\
(\mathrm{n} .119) \\
{[\mathrm{HR} \mathrm{0.99;}} \\
95 \% \mathrm{Cl}, \\
0.75-1.29]\end{array}$ & $\begin{array}{l}\text { Not } \\
\text { reported }\end{array}$ \\
\hline $\begin{array}{l}0007 \text { (III) } \\
\text { NCTOI } 4 \text { I } 2957 \\
80\end{array}$ & $\begin{array}{l}\text { Panitumumab } \\
\text { (n.189) } \\
\text { BSC (n.188) }\end{array}$ & $3 r d /+$ & OS & $\begin{array}{l}27 \% \\
1.6 \% \\
{[P<0.000 I]}\end{array}$ & $\begin{array}{l}31 \% \\
2.3 \% \\
{[P<0.0001]}\end{array}$ & $\begin{array}{l}3.6 \mathrm{~m} \\
(\mathrm{n} .189) \\
\mathrm{I} .7 \mathrm{~m} \\
(\mathrm{n} .188) \\
{[\mathrm{HR} 0.5 \mathrm{I} ;} \\
P<0.000 \mathrm{I}]\end{array}$ & $\begin{array}{l}5.2 \mathrm{~m} \\
(\mathrm{n} .142) \\
\mathrm{I} .7 \mathrm{~m} \\
(\mathrm{n} . \mathrm{I} 28) \\
{[\mathrm{HR} 0.46 ;} \\
P<0.000 \mathrm{I}]\end{array}$ & $\begin{array}{l}10 \mathrm{~m} \\
(\mathrm{n} .189) \\
7.4 \mathrm{~m} \\
(\mathrm{n} .188) \\
{[\mathrm{HR} 0.73 ;} \\
P=0.0096]\end{array}$ & $\begin{array}{l}10 \mathrm{~m} \\
(\mathrm{n} .142) \\
6.9 \mathrm{~m} \\
(\mathrm{n} .128) \\
{[\mathrm{HR} 0.70 ;} \\
P=0.0135]\end{array}$ \\
\hline $\begin{array}{l}\text { ASPECCT (III) } \\
\text { NCTOI00I } 377 \\
12\end{array}$ & $\begin{array}{l}\text { Panitumumab } \\
\text { (n.499) } \\
\text { Cetuximab } \\
\text { (n.500) }\end{array}$ & $3 r d /+$ & OS & $\begin{array}{l}22 \% \\
20 \%\end{array}$ & NE & $\begin{array}{l}4.1 \mathrm{~m} \\
\text { (n.499) } \\
4.4 \mathrm{~m} \\
\text { (n.500) } \\
\text { [HR I.00; } \\
95 \% \mathrm{Cl}, \\
0.88- \\
\text { I.I4] }\end{array}$ & NE & $\begin{array}{l}10.4 \mathrm{~m} \\
(\mathrm{n} .499) \\
10 \mathrm{~m} \\
(\mathrm{n} .500) \\
\text { [HR 0.97; } \\
\text { Z-score } \\
-3.19 ; \\
P=0.0007]\end{array}$ & NE \\
\hline $\begin{array}{l}\text { PRIME (III) } \\
\text { NCT003640I3 } \\
15,16\end{array}$ & $\begin{array}{l}\text { FOLFOX }+ \\
\text { Panitumumab } \\
\text { (n.593) } \\
\text { FOLFOX } \\
\text { (n.590) }\end{array}$ & Ist & PFS & $\begin{array}{l}57 \% \\
48 \% \\
{[P=0.02]}\end{array}$ & $\begin{array}{l}\text { Not } \\
\text { reported }\end{array}$ & 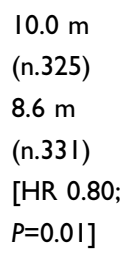 & 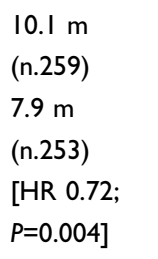 & $\begin{array}{l}23.8 \mathrm{~m} \\
(\mathrm{n} .325) \\
19.4 \mathrm{~m} \\
(\mathrm{n} .33 \mathrm{I}) \\
{[\mathrm{HR} 0.83 ;} \\
P=0.03]\end{array}$ & $\begin{array}{l}25.8 \mathrm{~m} \\
\text { (n.259) } \\
20.2 \mathrm{~m} \\
(\mathrm{n} .253) \\
{[\mathrm{HR} 0.77 ;} \\
P=0.009]\end{array}$ \\
\hline $\begin{array}{l}314 \text { (II) } \\
\text { NCT00508404 } \\
19,47\end{array}$ & $\begin{array}{l}\text { FOLFIRI + } \\
\text { Panitumumab } \\
\text { (n.I54) }\end{array}$ & Ist & ORR & $56 \%$ & $59 \%$ & $\begin{array}{l}8.9 \mathrm{~m} \\
(\mathrm{n} .86)\end{array}$ & $\begin{array}{l}11.2 \mathrm{~m} \\
(\mathrm{n} .68)\end{array}$ & $\begin{array}{l}\text { Not } \\
\text { Reported }\end{array}$ & $\begin{array}{l}\text { Not } \\
\text { reported }\end{array}$ \\
\hline $\begin{array}{l}\text { PEAK (II) } \\
\text { NCT008I9780 } \\
25,26\end{array}$ & $\begin{array}{l}\text { FOLFOX + } \\
\text { Panitumumab } \\
\text { (n. I42) } \\
\text { FOLFOX + } \\
\text { Bevacizumab } \\
\text { (n.143) }\end{array}$ & Ist & PFS & $\begin{array}{l}57.8 \% \\
53.5 \%\end{array}$ & $\begin{array}{l}65 \% \\
60 \%\end{array}$ & 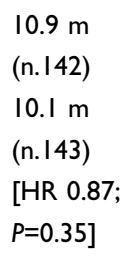 & $\begin{array}{l}12.8 \mathrm{~m} \\
(\mathrm{n} .88) \\
10.1 \mathrm{~m} \\
(\mathrm{n} .82) \\
{[\mathrm{HR} 0.68 ;} \\
P=0.029]\end{array}$ & $\begin{array}{l}34.2 \mathrm{~m} \\
(\mathrm{n} .142) \\
24.3 \mathrm{~m} \\
(\mathrm{n} .143) \\
{[H R 0.62 ;} \\
P=0.009]\end{array}$ & $\begin{array}{l}36.9 \mathrm{~m} \\
(\mathrm{n} .88) \\
28.9 \mathrm{~m} \\
(\mathrm{n} .82) \\
{[\mathrm{HR} \mathrm{0.76;}} \\
P=0.15]\end{array}$ \\
\hline $\begin{array}{l}\text { PLANET-TTD } \\
\text { (II) } \\
\text { NCT00885885 } \\
28\end{array}$ & $\begin{array}{l}\text { FOLFOX + } \\
\text { Panitumumab } \\
\text { (n.38) } \\
\text { FOLFIRI + } \\
\text { Panitumumab } \\
\text { (n.39) }\end{array}$ & Ist & ORR & $\begin{array}{l}74 \% \\
67 \%\end{array}$ & $\begin{array}{l}78 \% \\
73 \%\end{array}$ & $\begin{array}{l}13 \mathrm{~m} \\
\text { (n.38) } \\
14 \mathrm{~m} \\
\text { (n.39) } \\
{[H R 0.90 ;} \\
P=0.728]\end{array}$ & $\begin{array}{l}\text { I3 m (n.27) } \\
\text { I5 m (n.26) } \\
\text { [HR 0.70; } \\
P=0.307]\end{array}$ & $\begin{array}{l}37 \mathrm{~m}(\mathrm{n} .38) \\
4 I \mathrm{~m}(\mathrm{n} .39) \\
{[H R \quad .0 ;} \\
P=0.966]\end{array}$ & $\begin{array}{l}39 \mathrm{~m} \\
\text { (n.27) } \\
49 \mathrm{~m} \\
(\mathrm{n} .26) \\
{[\mathrm{HR} 0.9 ;} \\
P=0.824]\end{array}$ \\
\hline
\end{tabular}

(Continued) 
Table I (Continued).

\begin{tabular}{|c|c|c|c|c|c|c|c|c|c|}
\hline \multirow{2}{*}{$\begin{array}{l}\text { Trial (phase) } \\
\text { Ref }\end{array}$} & \multirow{2}{*}{$\begin{array}{l}\text { Treatment } \\
\text { Arms (n.) }\end{array}$} & \multirow{2}{*}{$\begin{array}{l}\text { Treatment } \\
\text { Line }\end{array}$} & \multirow{2}{*}{$\begin{array}{l}\text { Primary } \\
\text { Endpoint }\end{array}$} & \multicolumn{2}{|l|}{ ORR (\%) } & \multicolumn{2}{|l|}{ PFS } & \multicolumn{2}{|l|}{ os } \\
\hline & & & & $\begin{array}{l}\text { KRAS ex } \\
2 \text { WT }\end{array}$ & RAS WT & $\begin{array}{l}\text { KRAS ex } \\
2 \mathrm{WT}\end{array}$ & RAS WT & $\begin{array}{l}\text { KRAS ex } \\
2 \text { WT }\end{array}$ & RAS WT \\
\hline $\begin{array}{l}\text { VOLFI (II) } \\
\text { NCT0I328I7I } \\
35\end{array}$ & $\begin{array}{l}\text { mFOLFOXIRI } \\
+ \\
\text { Panitumumab } \\
\text { (n.63) } \\
\text { mFOLFOXIRI } \\
\text { (n.33) }\end{array}$ & Ist & ORR & - & $\begin{array}{l}87.3 \% \\
60.6 \% ; \\
{[P=0.004 I]}\end{array}$ & - & $\begin{array}{l}9.7 \mathrm{~m} \\
(\mathrm{n} .63) \\
\mathrm{I} 0.1 \mathrm{~m} \\
(\mathrm{n} .33) \\
{[\mathrm{HR} 0.92 ;} \\
P=0.72]\end{array}$ & $\begin{array}{l}\text { Not } \\
\text { Reported }\end{array}$ & $\begin{array}{l}\text { Not } \\
\text { Reported }\end{array}$ \\
\hline $\begin{array}{l}|8| \text { (III) } \\
\text { NCT00339|83 } \\
|3,| 4,8 \mid\end{array}$ & $\begin{array}{l}\text { FOLFIRI + } \\
\text { Panitumumab } \\
\text { (n.59I) } \\
\text { FOLFIRI } \\
\text { (n.595) }\end{array}$ & 2nd & PFS, OS & $\begin{array}{l}35 \% \\
10 \% \\
{[P<0.0001]}\end{array}$ & $\begin{array}{l}41 \% \\
10 \%\end{array}$ & 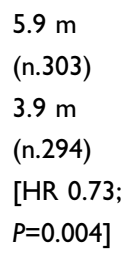 & $\begin{array}{l}6.4 \mathrm{~m} \\
(\mathrm{n} .208) \\
4.6 \mathrm{~m} \\
(\mathrm{n} .213) \\
{[\mathrm{HR} 0.70 ;} \\
P=0.007]\end{array}$ & 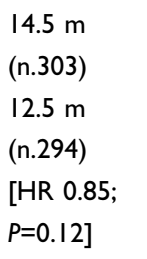 & $\begin{array}{l}16.2 \mathrm{~m} \\
(\mathrm{n} .303) \\
\mathrm{I} 3.9 \mathrm{~m} \\
(\mathrm{n} .294) \\
{[H R \quad 0.8 \mathrm{I} ;} \\
P=0.08]\end{array}$ \\
\hline $\begin{array}{l}\text { SPIRITT (II) } \\
\text { NCT004I8938 } \\
82\end{array}$ & $\begin{array}{l}\text { FOLFIRI + } \\
\text { Panitumumab } \\
\text { (n.9l) } \\
\text { FOLFIRI + } \\
\text { Bevacizumab } \\
\text { (n.9l) }\end{array}$ & 2nd & PFS & $\begin{array}{l}32 \% \\
19 \%\end{array}$ & NE & $\begin{array}{l}7.7 \mathrm{~m} \\
(\mathrm{n} .9 \mathrm{I}) \\
9.2 \mathrm{~m} \\
(\mathrm{n} .9 \mathrm{I}) \\
{[\mathrm{HR} \text { I.0I; }} \\
P=0.97]\end{array}$ & NE & $\begin{array}{l}18 \mathrm{~m}(\mathrm{n} .91) \\
21.4 \mathrm{~m} \\
(\mathrm{n} .91) \\
{[H R \quad .06 ;} \\
P=0.75]\end{array}$ & NE \\
\hline
\end{tabular}

Abbreviations: BSC, best supportive care; Cl, confidence interval; ex, exon; HR, hazard ratio; m, months; n, number of patients; NE, not evaluated; PFS, progression free survival; ORR, objective response rate; OS, overall survival; Ref, reference; WT, wild-type.

panitumumab (Sequence 2) in untreated patients with unresectable RAS WT left-sided mCRC (NCT03635021).

Of note, panitumumab treatment was consistently associated with higher early tumor shrinkage (ETS) rates and greater depth of response $(\mathrm{DpR})$ in a large retrospective analysis of patients with $R A S$ WT mCRC from the randomized first-line PRIME, PEAK and PLANET ${ }^{28}$ trials. Irrespective of treatment, ETS and DpR were associated with improved PFS, OS and resection rates in this analysis, suggesting that achieving these endpoints during firstline treatment is linked with favorable outcomes. ${ }^{29}$

In the third-line setting, regorafenib and trifluridine/tipiracil are recommended after progression to standard cytotoxic and targeted treatments. However, in $R A S$ WT patients not previously treated with anti-EGFR antibodies, cetuximab in combination with irinotecan or panitumumab monotherapy may be considered as a third-line. Of interest, in the context of the continuum of care of mCRC patients, several studies and case reports have reported data about different treatment strategies in second- or third-line, including the reintroduction or re-challenge with cetuximab or panitumumab in patients who have been previously treated with anti-EGFR drugs as a first-line. ${ }^{30,31}$ Despite promising results, further perspective trials are warranted to establish the role of this strategy in the third-line setting in $R A S \mathrm{WT}$ mCRC patients (see paragraph 6). ${ }^{32}$

\section{Combination with intensified chemotherapy}

Panitumumab has also been tested in combination with the triple chemotherapy regimen FOLFOXIRI in several small studies.

In 2013, a single arm phase II trial enrolled 37 patients with quadruple WT $(K R A S, N R A S, H R A S$, $B R A F$ ) initially unresectable $\mathrm{mCRC}$ to receive treatment with panitumumab in association to a modified FOLFOXIRI regimen. ${ }^{33}$ Median PFS was 11.3 months. The ORR, primary endpoint of the study, was $89 \%$ with one complete response, allowing 16 metastases resection, 13 of which (35\%) R0. Another single arm phase II trial assessing the efficacy of FOLFOXIRI plus panitumumab in $R A S$ WT tumors was published in $2016 .{ }^{34}$ ORR was $59 \%$ (no complete responses) and 10 patients (66\%) underwent surgery and secondary R0 resection. Median PFS was 13.3 months. 
More recently, promising results were presented from the randomized phase II VOLFI trial, which enrolled 96 patients with unresectable $R A S$ WT mCRC to receive either mFOLFOXIRI plus panitumumab or FOLFOXIRI alone. ${ }^{35}$ First-line treatment with mFOLFOXIRI plus panitumumab resulted in significantly higher ORR compared to chemotherapy alone (87.3\% versus $60.6 \%$; OR: $4.47 ; 95 \%$ CI, 1.61-12.38; $P=0.0041)$, and higher disease control rate (DCR) $(97 \%$ versus $79 \%, P=0.0071)$. Secondary resection rates were $33.3 \%$ in the anti-EGFR arm $(61.9 \% \mathrm{R} 0)$ versus $12.1 \%$ in the chemotherapy-only arm in the overall population, and $75 \%$ versus $36.4 \%$ in the potentially resectable cohort. Median PFS was not significantly different between treatment arms in the overall population.

To clarify whether the intensification of chemotherapy treatment in combination with panitumumab may be beneficial, two trials are currently ongoing. The phase III TRIPLETE trial is testing the efficacy of FOLFOXIRI plus panitumumab versus mFOLFOX6 plus panitumumab in previously untreated RAS/BRAF WT mCRC (NCT03231722). The phase II PANIRINOX trial is assessing treatment with FOLFIRINOX plus panitumumab versus mFOLFOX6 plus panitumumab (NCT02980510). Results of these trials are warranted to further evaluate the efficacy and safety of this intensified treatment strategy.

\section{Maintenance treatment}

Maintenance treatment with the anti-VEGF bevacizumab in combination with a fluoropyrimidine after a period of induction therapy in patients with a good response to the initial treatment has become a standard of care for mCRC and is included in main international guidelines. On the other hand, there is less evidence on maintenance strategies involving anti-EGFR mAbs.

The role of continuing panitumumab as a maintenance therapy after first-line treatment was firstly evaluated in a retrospective analysis of patients from the PRIME and PEAK trials receiving maintenance therapy with panitumumab plus 5-fluorouracil/leucovorin (5-FU/LV). ${ }^{36}$ Overall, the median duration of panitumumab maintenance was 21 weeks (interquartile range: 11-41). The analysis showed an OS and PFS benefit in continuing the administration of panitumumab in addition to 5-FU/LV versus chemotherapy \pm bevacizumab, with PRIME patients having a median OS of 40.2 versus 24.1 months and PEAK patients a median OS of 39.1 versus 28.9 months, respectively.

More recently, the phase II VALENTINO study investigated the efficacy of a maintenance treatment with $5 \mathrm{FU} / \mathrm{LV}$ plus panitumumab versus single-agent panitumumab following first-line FOLFOX plus panitumumab in patients with $R A S$ WT mCRC. This study showed that maintenance with panitumumab alone following induction with FOLFOX plus panitumumab achieves inferior PFS than the $5 \mathrm{FU} / \mathrm{LV}$ plus panitumumab combination: 10-months PFS 52.8\% versus $62.8 \%$, median PFS 10.2 versus 13 months, respectively $(P=0.011){ }^{37}$

Data from the Japanese phase II SAPPHIRE trial, where patients not progressing after 6 cycles of FOLFOX plus panitumumab were randomized to receive 5-FU/LV and panitumumab as maintenance therapy or to continue induction treatment, showed similar 9-months PFS in the two arms, thus supporting the use of panitumumab plus 5-FU/LV as a maintenance treatment in order to delay disease progression while preventing the occurrence of oxaliplatin-induced neuropathy. ${ }^{38}$

\section{Tumor sidedness in panitumumab trials}

Over the past few years, several studies highlighted the prognostic value of primary tumor location (left colon versus right colon) and data have focused on location as a potential predictive biomarker for anti-EGFRs activity, especially in the first-line setting. In particular, left-sided primary tumors have been shown to have better prognosis and improved treatment outcomes from the use of EGFR inhibitors in addition to combination chemotherapy.

Data from 927 patients with extended $R A S$ WT mCRC enrolled in three randomized trials on panitumumab (PRIME, PEAK and 181) showed that the overall prognosis was worse for right-sided tumors than for left-sided ones, regardless of treatment. The addition of panitumumab to chemotherapy led to striking PFS and OS outcomes in left-sided tumors; conversely, patients with $R A S$ WT right-sided primary tumors derived no benefit from the addition of anti-EGFRs to chemotherapy. A higher proportion of patients with right-sided tumors harbored $B R A F$ mutations, thus contributing to the worse prognosis of this group, nevertheless, similar efficacy data were also obtained in the RAS/BRAF WT population. ${ }^{39}$ Similar results were found consistently across several different trials of panitumumab in second- and later-lines of treatment, ${ }^{40}$ and trials investigating cetuximab-based treatments. ${ }^{41} \mathrm{~A}$ more recent retrospective analysis of patients with RAS WT mCRC from the PRIME and PEAK trials further evaluated the effects of primary tumor location on ETS, DpR, and long-term survival. First-line panitumumab was associated with improved 
ETS (PRIME: $62 \%$ versus $36 \%$; PEAK: $58 \%$ versus $41 \%$ ) and DpR (PRIME: $59 \%$ versus $49 \%$; PEAK: $70 \%$ versus $48 \%$ ) in patients with left-sided $\mathrm{mCRC}$, and panitumumab treatment consistently predicted long-term survival. Notably, in the pooled analyses of the studies, more patients with right-sided disease achieved ETS if treated with panitumumab than comparator (39\% versus $29 \%$ ), thus ETS may identify a subgroup of patients with rightsided disease who might respond to panitumumab. ${ }^{42}$

Large meta-analyses of first-line trials comparing chemotherapy plus bevacizumab to chemotherapy plus antiEGFRs have shown a significant benefit in ORR, PFS and OS in patients with left-sided primary tumors treated with anti-EGFR mAbs compared to bevacizumab, whereas right-sided tumors have been shown to be a negative prognostic indicator for OS for all treatments and to benefit more from bevacizumab treatment. ${ }^{43,44}$

Several hypotheses have been proposed to explain these findings, involving the role of different embryogenic origin, the association of right-sided tumors with specific molecular phenotypes (particularly, CMS1-immune and CMS3-metabolic), different methylation signatures and the distinct microbiota in right versus left colon, supporting the role of tumor sidedness as a surrogate for tumor biology. ${ }^{45}$

A limitation of these data is the unplanned retrospective nature of the abovementioned analyses, however, in light of their consistency across a number of different randomized trials, NCCN guidelines have recently incorporated into their recommendation to exclude anti-EGFR antibodies in the first-line treatment of right-sided $R A S$ WT mCRC. ${ }^{2}$

It has to be noted, however, that when selecting the optimal treatment strategy for a $R A S \mathrm{WT}$ mCRC patient a comprehensive evaluation of the clinical scenario, treatment goals, expected toxicities and patients' characteristics and preferences must be taken into account, leading to a personalized approach that may favor, for instance, an anti-VEGF therapy as first-line for a left-sided RAS WT $\mathrm{mCRC}$, saving anti-EGFR agents for a later treatment line.

\section{Quality of life, safety and tolerability}

Anti-EGFR therapy frequently results in skin-related toxicities (eg acneiform rash, xerosis, paronychia). These side effects can negatively affect treatment compliance and patients' quality of life (QoL) ${ }^{46}$ and it is important to evaluate how the impact of such adverse events weigh against the benefits of panitumumab in $\mathrm{mCRC}$ patients.
Therefore, maintenance of QoL is an important objective in clinical trials and patient-reported outcomes (PROs) are a useful way of measuring the impact of treatment on QoL.

Study 314 was a single-arm, multicenter, phase II study evaluating the efficacy and safety of panitumumab plus FOLFIRI as first-line treatment for patients with mCRC. ${ }^{47}$ In this trial, QoL was measured using the EuroQoL 5domain (EQ-5D) and the EORTC QoL Questionnaires (QLQ-C30) as an exploratory endpoint. Notably, panitumumab plus FOLFIRI had minimal impact on patients' QoL, as EQ-5D and QLQ-C30 scores remained stable throughout the study despite the high incidence of skinrelated toxicity. ${ }^{48}$

In the PRIME trial, ${ }^{15}$ QoL was assessed as a prespecified tertiary endpoint, using the EQ-5D health state index (HSI) and overall health rating (OHR) measures. There were no statistically significant differences between the panitumumab plus FOLFOX4 and FOLFOX4 arms in HSI or OHR scores from baseline to progression or to discontinuation. ${ }^{49}$ Of interest, in this study the authors assessed whether skin toxicities and early tumor shrinkage (ETS) may have had impact on QoL. However, no significant differences in QoL outcomes were observed between patients with grade $(\mathrm{G})$ 0-2 skin toxicity and those with G3+ skin toxicity, as well as no difference in QoL for those with ETS versus those without ETS. Nonetheless, patients with tumor-related symptoms at baseline who experienced ETS showed a statistically meaningful improvement in QoL compared with those who did not have ETS.

The evaluation of changes in health-related QoL (HRQoL) using the EQ-5D was a tertiary objective also in the second-line phase III 181 trial. ${ }^{13}$ A total of 530 patients (263 treated with panitumumab plus FOLFIRI and 267 with FOLFIRI) were included in the HRQoL analysis, representing $88.8 \%$ of the overall KRAS WT population. There were no statistically significant or clinically meaningful overall differences in the change in HRQoL when comparing treatment arms. In addition, regardless of the severity of skin toxicity, patients treated with panitumumab maintained a similar HRQoL. ${ }^{50}$

Panitumumab has also been reported to provide better control of symptoms and maintenance of HRQoL compared with BSC alone in patients with chemorefractory KRAS WT mCRC. ${ }^{51}$

Taken together, these data suggest that the addition of panitumumab to chemotherapy regimens as a first-, 
second- or later-line treatment of patients with $R A S$ WT mCRC provides improvements in survival outcomes without compromising HRQoL.

Safety and tolerability data are available from clinical trials evaluating panitumumab as a monotherapy or in combination with chemotherapy in mCRC. Based on a pooled analysis of patients enrolled in panitumumab trials $(n=2,224)$, the most commonly reported adverse reactions (AE) are skin reactions occurring in approximately $94 \%$ of patients, including rash (47\%), dermatitis acneiform (39\%), pruritus $(36 \%)$, erythema $(33 \%)$, dry skin $(21 \%)$, and paronychia (20\%). Other very commonly reported AE occurring in $\geq 20 \%$ of patients are diarrhea ( $46 \%$ ), nausea (39\%), vomiting $(26 \%)$, constipation (23\%), abdominal pain $(23 \%)$, fatigue $(35 \%)$, pyrexia $(21 \%)$, and decreased appetite $(30 \%) .^{52}$

In phase II trials, the most frequent panitumumabrelated AE involved skin (92-96\%), nails (28-30\%), eyes $(8-17 \%)$, hair $(8 \%){ }^{53}$ EGFR is expressed in normal skin cells; therefore, dermatologic AE are directly linked to EGFR blockade. Acneiform rash usually appears after the first treatment administration, while paronychia and desquamation usually appear by the fourth week of treatment. $^{54}$ In a pooled analysis of 920 patients treated with panitumumab monotherapy included in ten phase IIII clinical trials most patients experienced G1-2 skin toxicities that rarely resulted in treatment discontinuation. Importantly, the development of skin toxicities $\geq \mathrm{G} 2$ has been associated with improved PFS and OS $;^{55}$ therefore, it is considered a strong predictive biomarker of clinical benefit in patients treated with EGFR inhibitors.

Since these toxicities can result in treatment discontinuation and can potentially affect the patient's QoL, increase patient risk for additional infections, and lead to suboptimal anti-EGFR schedules -all of which may affect clinical outcomes- their management should be an important focus when administering these agents. ${ }^{56}$ Hence, novel strategies to reduce the incidence and the severity of skin toxicity have been developed based on the STEPP $^{54}$ (Skin Toxicity Evaluation Protocol with Panitumumab) and J-STEPP ${ }^{57}$ randomized studies. The randomized phase II STEPP study evaluated the impact of a pre-emptive strategy (primary prophylaxis) including skin moisturizers, sunscreen, topical steroids, and doxycycline for the duration of anti-EGFR therapy, versus a reactive treatment after toxicity occurrence. ${ }^{54}$ The preemptive strategy significantly reduced the incidence of $\geq \mathrm{G} 2$ skin toxicity at 6 weeks compared to standard care
(29\% versus $62 \%$, respectively). Similarly, the Japanese open-label, multicenter, randomized J-STEPP study showed that the cumulative incidence of $\geq \mathrm{G} 2$ skin toxicities in 6 weeks was $21.3 \%$ in the pre-emptive group compared with $62.5 \%$ in the reactive group $(\mathrm{RR}=0.34$; 95\% CI, 0.19-0.62; $P<0.001) .^{57}$

Panitumumab administration should be withheld at the first occurrence of G3 skin toxicities. Re-introduction of panitumumab at the original dose is recommended once toxicity has subside, while dose reduction is recommended upon subsequent occurrence of G3 toxicities $(80 \%$ of the original dose at the second occurrence and $60 \%$ at the third occurrence). ${ }^{4}$ Discontinuation of treatment is implemented at the forth occurrence or if G3 skin toxicities do not recover after 1-2 withheld doses.

When panitumumab is administered as monotherapy severe diarrhea is uncommon, however its incidence increases when panitumumab is associated with chemotherapy. In fact, G3-4 diarrhea occurred in up to $28 \%$ of patients in trials combining an EGFR inhibitor with chemotherapy. ${ }^{58}$

Another common AE that may occur during panitumumab treatment is hypomagnesemia, due to the effects of EGFR inhibition in the ascending loop of Henle and in the distal convoluted renal tubule. Incidence of hypomagnesemia can be up to $28-36 \%$ and was found to be associated with treatment duration. ${ }^{59}$ In most cases panitumumabinduced hypomagnesemia is asymptomatic, however for patients who experience a symptomatic $\geq \mathrm{G} 2$ hypomagnesemia, oral or intravenous replacement should be considered. Of interest, early onset of hypomagnesemia during anti-EGFR treatment has been associated with treatment efficacy. $^{60}$

Panitumumab is a fully human $\mathrm{mAb}$, hence incidence of infusion-related reactions is very low (1-3\%). The use of routine premedication before the administration of panitumumab is recommended if a previous infusion reaction has occurred. ${ }^{4}$

\section{Panitumumab in the elderly population}

Despite the high prevalence of CRC in the elderly population, these patients have been underrepresented in clinical trials and their optimal treatment is yet to be determined, with only few data available on anti-EGFR treatment in combination with chemotherapy. In the daily practice, treatment of older cancer patients is challenging and a 
careful assessment of patients' performance status, comorbidities, age-related organ function, life expectancy, potential treatment-related toxicity and QoL issues should be implemented in the decision making to select those patients who could benefit from treatment.

The use of panitumumab as monotherapy in the firstline setting in elderly and frail patients was investigated by Sastre and colleagues, who treated 33 KRAS WT patients over 70 years of age with an ECOG functional status up to 3 in a single arm phase II trial. Treatment with panitumumab was demonstrated to be an active and safe option in this group of patients. ORR was $9.1 \%$ with a 6 -months PFS rate of $53.3 \%$ and median OS of 12.3 months in the extended $R A S$ WT patients. ${ }^{61}$ Encouraging data were also reported in another study investigating panitumumab monotherapy in molecularly selected $R A S$ and $B R A F$ WT frail elderly patients deemed unfit for chemotherapy. ${ }^{62}$

However, data on the adoption of chemotherapy plus anti-EGFRs in elderly mCRC patients are scarce. In the subgroup analysis of $R A S$ WT patients from the PRIME study the combination of FOLFOX-4 and panitumumab showed a benefit over FOLFOX-4 in the subset of patients aged more than 65 years $(\mathrm{n}=188)$, in terms of OS $(26.6$ versus 17.4 months; HR 0.78 ; 95\% CI, 0.58-1.09), PFS (9.7 versus 9.2 months; HR 0.88 ; $95 \% \mathrm{CI}, 0.65-1.19$ ) and ORR ( $49 \%$ versus $42 \%$ ), without raising any safety concern. ${ }^{63}$ Positive results in terms of tolerability and efficacy were also recently reported in a retrospective study of 100 patients aged over 70 years $(95.4 \%$ ECOG performance status $0-1)$ treated with doublet chemotherapy plus panitumumab, with a median PFS of 9.4 months (95\% CI, 7.8-11.0) and a median OS of 23.0 months $(95 \%$ CI, 20.6-25.3). ${ }^{64}$

To clarify the safety and efficacy of panitumumab in association with chemotherapy in the elderly population a dedicated trial, the phase II PANDA study (NCT02904031), is currently ongoing, enrolling patients over 70 years of age with an ECOG performance status 1 or 2 if aged 70 to 75 years and an ECOG performance status 0 or 1 if aged $>75$ years. In this study elderly patients with a diagnosis of $R A S$ and $B R A F$ WT mCRC are randomized to a first-line treatment with panitumumab in combination with FOLFOX or $5 \mathrm{FU} / \mathrm{LV}$. Of note, secondary endpoints of the study include the evaluation of the prognostic role of geriatric assessment tools and toxicity risk scores to aid patient selection in the elderly population. Safety and efficacy results of this trial are warranted to inform targeted treatment choices in elderly patients.

\section{Novel mechanisms of resistance and future perspectives}

Several additional mechanisms of primary resistance to anti-EGFRs have been identified in RAS WT mCRC so far, based on preclinical data and retrospective evaluations. However, the routine use of these biomarkers in clinical practice is not recommended at present, and further prospective validation is warranted. These include HER2 amplification, PIK3CA mutations (exon 9 and 20), MET amplification, FGFR1 and PDGFRA mutations and loss of PTEN function. ${ }^{65}$ HER2 amplification, in particular, has recently gained attention as a promising druggable target in mCRC. Based on a strong pre-clinical rationale, ${ }^{66}$ the proof-of-concept phase II HERACLES trial has shown promising activity of a combined HER2 blockade with trastuzumab and lapatinib in treatment-refractory HER2positive mCRC.$^{67}$ Notably, all patients enrolled in the trial received previous EGFR inhibitors and none of those evaluable for response achieved an objective response to either panitumumab or cetuximab, supporting the role of HER2 amplification as a resistance mechanism to antiEGFRs. Several trials are currently investigating HER2 blockade strategies in HER2-amplified mCRC, opening new perspectives for this subset of patients. Other novel treatment strategies combining EGFR inhibitors with different targeted agents (ie panitumumab plus the mTOR inhibitor everolimus, ${ }^{68}$ or panitumumab plus BRAF and MEK inhibition in BRAFV600E-mutant tumors ${ }^{69}$ ), aiming to overcome primary resistance to anti-EGFR agents, are also under investigation.

More recently, a panel of multiple combined genomic alterations comprising activating mutations of the MAPKs or PI3K/AKT axis, NTRK/ROS1/ALK/RET rearrangements, HER2 amplification or mutations, and MET amplification (the PRESSING panel), has been shown to be able to predict primary resistance to anti-EGFRs in $R A S / B R A F$ WT mCRCs. ${ }^{70}$ Additionally, a right-sided primary tumor location was found to be associated with resistance to anti-EGFRs, confirming previous literature evidence. Overall, the combined evaluation of the PRESSING panel and primary tumor location demonstrated the best predictive accuracy. These results open novel perspectives on the clinical application of a more comprehensive molecular characterization of $R A S / B R A F$ WT mCRCs to further improve and refine patient selection for anti-EGFR treatment and possibly tailor personalized targeted approaches. 
Clonal selection induced by treatment pressure is often responsible for the development of secondary resistance to EGFR inhibitors, and emerging mutations in the RAS/ RAF/MAPK pathway can be identified in tumor samples at progression in patients previously diagnosed with a $R A S$ WT tumors. ${ }^{71}$ Several trials are investigating different approaches to multiple target inhibition based on the emergence of different resistance drivers. In this setting, the use of liquid biopsies and the analysis of circulating tumor DNA (ctDNA) are being evaluated as a less invasive and more comprehensive approach to pharmacogenomic profiling and biomarkers monitoring in mCRC patients. ${ }^{72}$ These techniques might play, in the near future, a pivotal role in improving patient selection and targeted treatment strategies by implementing early detection of the emergence of treatment resistance and allowing a dynamic molecular profiling. ${ }^{73}$ Indeed, repeated ctDNA analyses have been able to capture the emergence of resistant clones during treatment with panitumumab or cetuximab in $R A S$ WT patients, showing that this phenomenon is closely related to treatment exposure, with a dynamic increase during anti-EGFRs administration followed by a rapid decline at withdrawal. ${ }^{74,75}$ In a recent biomarker analysis from a second-line phase II trial of panitumumab in association with irinotecan in KRAS WT mCRC, plasma testing of cell-free DNA revealed a mutant $R A S$ emergence rate of $36.7 \%(\mathrm{n}=39)$, and first detected emergence of $R A S$ mutations preceded progression by a median of 3.6 months (range, 0.3-7.5). ${ }^{76}$ However, patients who had emergent $R A S$ mutations at progression had similar median PFS to those who remained WT and a mutant $R A S$ allele frequency threshold that could predict near-term outcomes was not identified, thus calling for further evaluation of the clinical value of this approach. Interestingly, recently published results from retrospective analyses evaluating emergent mutations in circulating cell-free DNA in patients treated with panitumumab in the ASPECCT study showed that patients with a higher $R A S$ mutant allele frequency at baseline had worse clinical outcomes than those with a lower frequency $(P<0.001)$. However, extended $R A S$ mutation, by itself, did not preclude clinical responses to panitumumab in this setting and emergent ctDNA RAS mutations were not associated with less favorable patient outcomes in panitumumab-treated patients. ${ }^{77,78}$ Further research is needed to identify a clinically relevant threshold for baseline and emergent ctDNA RAS mutations.

Of note, focusing on the issue of analytical sensitivity in evaluating predictive biomarkers to anti-EGFR treatments, the phase II ULTRA trial investigated a high-sensitivity tumor tissue genotyping technique of KRAS, NRAS, BRAF and PIK3CA to ultra-select irinotecan-resistant mCRC patients for panitumumab plus FOLFIRI treatment. Results from this study identify the optimal $R A S / B R A F$ mutational threshold for outcome prediction to be $5 \%$, suggesting that the biological and clinical implications of mutation frequencies below this cut-off still warrant further investigations. $^{79}$

Finally, re-challenge strategies after treatment breaks in patients with $R A S$ WT tumors that demonstrated a previous response to anti-EGFR agents are currently under study. The phase II CHRONOS study (NCT03227926) aims to investigate a re-challenge strategy with panitumumab as third-line treatment after a first-line treatment with anti-EGFRs in $R A S / B R A F$ WT mCRC, with a molecular follow-up based on ctDNA. In this study liquid biopsies for ctDNA testing are prospectively collected during the first-line and the re-challenge phases to test the correlation between circulating ctDNA biomarkers and treatment response. Interestingly, the possibility of continuing panitumumab beyond progression is also being investigated in a multicenter single-arm phase II Japanese clinical trial of second-line FOLFIRI plus panitumumab after first-line treatment with FOLFOX plus panitumumab in initial RAS WT mCRC (UMIN000026817). Mutational status using ctDNA will be prospectively assessed at multiple time-points during this study as one of the planned secondary endpoints.

\section{Conclusions}

Panitumumab in association with chemotherapy is a valuable first- or second-line treatment option in patients with $R A S$ WT mCRC, as well as a monotherapy option in advanced lines for chemorefractory patients. The toxicity profile of panitumumab is manageable and this agent has a favorable impact on patient's QoL, showing positive results also in the population of frail and elderly mCRC patients. Novel treatment scenarios are opening for panitumumab including combinations with intensified chemotherapy regimens to implement conversion to resectability in initially unresectable patients and maintenance treatment strategies. The development of panitumumab has significantly added to the treatment options for $R A S$ WT mCRC, and has contributed to expanding the horizons of mCRC molecular profiling.

Current efforts are directed to dissect the mechanisms of primary resistance beyond $R A S$ status and the 
mechanisms of acquired resistance to panitumumab (and more generally anti-EGFRs), which entails a more comprehensive molecular characterization of $R A S$ WT tumors, the assessment of additional mutational and clinico-pathological features, ie $B R A F$ status and tumor sidedness, and the development of novel technologies to capture the dynamic heterogeneity of the genomic landscape displayed by mCRC under targeted treatment pressure. Recent advancements in this field warrant a prospective validation of new predictive biomarkers in $R A S$ WT mCRC, in order to further refine patient selection and develop novel molecularly-tailored treatment strategies to optimize outcomes and patients benefit.

\section{Acknowledgments}

This manuscript was partly supported by the National Cancer Institute (grant number P30CA014089), the Gloria Borges WunderGlo Foundation-The Wunder Project, the Dhont Family Foundation, the San Pedro Peninsula Cancer Guild, the Daniel Butler Research Fund, the Call to Cure Research Fund, and the Fong Research Project. The content is solely the responsibility of the authors and does not necessarily represent the official views of the National Cancer Institute or the National Institutes of Health. Francesca Battaglin and Alberto Puccini are co-first authors for this study.

\section{Author contributions}

All authors contributed to data analysis, drafting and revising the article, gave final approval of the version to be published, and agree to be accountable for all aspects of the work.

\section{Disclosure}

FB has received travel/accommodations from Bayer and Amgen Inc. HJL has received clinical trial financial support from Merck Serono and Roche, honoraria for advisory board membership and lectures from Bayer, Boehringer Ingelheim, Genentech, Pfizer, Merck Serono and Roche, and travel/accommodations from Bayer, Merck Serono and Roche. The authors report no other conflicts of interest in this work.

\section{References}

1. Siegel RL, Miller KD, Jemal A. Cancer statistics, 2018. CA Cancer J Clin. 2018;68(1):7-30.

2. National Comprehensive Cancer Network. Clinical practice guidelines in oncology. Colon Cancer. Version 1.2019. Available from: https://www.ncen. org/professionals/physician_gls/pdf/colon.pdf Accessed April 01, 2019.
3. Cremolini $\mathrm{C}$, Schirripa $\mathrm{M}$, Antoniotti $\mathrm{C}$, et al. First-line chemotherapy for mCRC-a review and evidence-based algorithm. Nat Rev Clin Oncol. 2015;12(10):607-619. doi:10.1038/nrclinonc.2015.129

4. Vectibix ${ }^{\circledR}$ (Panitumumab). Thousand Oaks, CA: Amgen Inc.; 2017. Available from: https://www.accessdata.fda.gov/drugsatfda_docs/ label/2017/125147s2071bl.pdf. Accessed January 16, 2019.

5. Citri A, Yarden Y. EGF-ERBB signalling: towards the systems level. Nat Rev Molecular Cell Biol. 2006;7(7):505-516. doi:10.1038/nrm1962

6. Yang BB, Lum P, Chen A, et al. Pharmacokinetic and pharmacodynamic perspectives on the clinical drug development of panitumumab. Clin Pharmacokinet. 2010;49(11):729-740. doi:10.2165/ 11535970-000000000-00000

7. Giannopoulou E, Antonacopoulou A, Matsouka P, Kalofonos HP. Autophagy: novel action of panitumumab in colon cancer. Anticancer Res. 2009;29(12):5077-5082.

8. Allegra CJ, Rumble RB, Hamilton SR, et al. Extended RAS gene mutation testing in metastatic colorectal carcinoma to predict response to anti-epidermal growth factor receptor monoclonal antibody therapy: american society of clinical oncology provisional clinical opinion update 2015. J Clin Oncol. 2016;34(2):179-185. doi:10.1200/JCO.2015.63.9674

9. Sepulveda AR, Hamilton SR, Allegra CJ, et al. Molecular biomarkers for the evaluation of colorectal cancer: guideline from the American society for clinical pathology, college of American pathologists, association for molecular pathology, and American society of clinical oncology. $J \mathrm{Mol}$ Diagn. 2017;19(2):187-225. doi:10.1016/j.jmoldx.2016.11.001

10. Van Cutsem E, Peeters M, Siena S, et al. Open-label phase III trial of panitumumab plus best supportive care compared with best supportive care alone in patients with chemotherapy-refractory metastatic colorectal cancer. $J$ Clin Oncol. 2007;25(13):1658-1664. doi: 10.1200/JCO.2006.08.1620

11. Amado RG, Wolf M, Peeters M, et al. Wild-type KRAS is required for panitumumab efficacy in patients with metastatic colorectal cancer. $J$ Clin Oncol. 2008;26(10):1626-1634. doi:10.1200/JCO.2007.14.7116

12. Price TJ, Peeters M, Kim TW, et al. Panitumumab versus cetuximab in patients with chemotherapy-refractory wild-type KRAS exon 2 metastatic colorectal cancer (ASPECCT): a randomised, multicentre, open-label, non-inferiority phase 3 study. Lancet Oncol. 2014;15 (6):569-579. doi:10.1016/S1470-2045(14)70118-4

13. Peeters M, Price TJ, Cervantes A, et al. Randomized phase III study of panitumumab with fluorouracil, leucovorin, and irinotecan (FOLFIRI) compared with FOLFIRI alone as second-line treatment in patients with metastatic colorectal cancer. J Clin Oncol. 2010;28 (31):4706-4713. doi:10.1200/JCO.2009.27.6055

14. Peeters M, Oliner KS, Price TJ, et al. Analysis of KRAS/NRAS mutations in a phase III study of panitumumab with FOLFIRI compared with FOLFIRI alone as second-line treatment for metastatic colorectal cancer. Clin Cancer Res. 2015;21(24):5469-5479. doi:10.1158/1078-0432.CCR-15-0526

15. Douillard JY, Siena S, Cassidy J, et al. Randomized, phase III trial of panitumumab with infusional fluorouracil, leucovorin, and oxaliplatin (FOLFOX4) versus FOLFOX4 alone as first-line treatment in patients with previously untreated metastatic colorectal cancer: the PRIME study. J Clin Oncol. 2010;28(31):4697-4705. doi:10.1200/JCO.2009.27.4860

16. Douillard JY, Siena S, Cassidy J, et al. Final results from PRIME: randomized phase III study of panitumumab with FOLFOX4 for firstline treatment of metastatic colorectal cancer. Ann Oncol. 2014;25 (7):1346-1355. doi:10.1093/annonc/mdu141

17. Therkildsen C, Bergmann TK, Henrichsen-Schnack T, Ladelund S, Nilbert M. The predictive value of KRAS, NRAS, BRAF, PIK3CA and PTEN for anti-EGFR treatment in metastatic colorectal cancer: a systematic review and meta-analysis. Acta Oncol. 2014;53(7):852864. doi:10.3109/0284186X.2014.895036

18. Douillard JY, Oliner KS, Siena S, et al. Panitumumab-FOLFOX4 treatment and RAS mutations in colorectal cancer. $N$ Engl $J$ Med. 2013;369(11):1023-1034. doi:10.1056/NEJMoa1305275 
19. Karthaus M, Hofheinz RD, Mineur L, et al. Impact of tumour RAS/ BRAF status in a first-line study of panitumumab + FOLFIRI in patients with metastatic colorectal cancer. Br J Cancer. 2016;115 (10):1215-1222. doi:10.1038/bjc.2016.343

20. Peeters M, Oliner KS, Parker A, et al. Massively parallel tumor multigene sequencing to evaluate response to panitumumab in a randomized phase III study of metastatic colorectal cancer. Clin Cancer Res. 2013;19(7):1902-1912. doi:10.1158/1078-0432.CCR12-1913

21. Sorich MJ, Wiese MD, Rowland A, Kichenadasse G, McKinnon RA, Karapetis CS. Extended RAS mutations and anti-EGFR monoclonal antibody survival benefit in metastatic colorectal cancer: a metaanalysis of randomized, controlled trials. Ann Oncol. 2015;26 (1):13-21. doi:10.1093/annonc/mdu378

22. Rowland A, Dias MM, Wiese MD, et al. Meta-analysis of BRAF mutation as a predictive biomarker of benefit from anti-EGFR monoclonal antibody therapy for RAS wild-type metastatic colorectal cancer. Br J Cancer. 2015;112(12):1888-1894. doi:10.1038/bjc.2015.173

23. Pietrantonio F, Petrelli F, Coinu A, et al. Predictive role of BRAF mutations in patients with advanced colorectal cancer receiving cetuximab and panitumumab: a meta-analysis. Eur J Cancer. 2015;51(5):587-594. doi:10.1016/j.ejca.2015.01.054

24. van Brummelen EMJ, de Boer A, Beijnen JH, Schellens JHM. BRAF mutations as predictive biomarker for response to anti-EGFR monoclonal antibodies. Oncologist. 2017. doi:10.1634/theoncologist.20170031

25. Schwartzberg LS, Rivera F, Karthaus M, et al. PEAK: a randomized, multicenter phase II study of panitumumab plus modified fluorouracil, leucovorin, and oxaliplatin (mFOLFOX6) or bevacizumab plus mFOLFOX6 in patients with previously untreated, unresectable, wild-type KRAS exon 2 metastatic colorectal cancer. J Clin Oncol. 2014;32(21):2240-2247. doi:10.1200/JCO.2013.53.2473

26. Rivera F, Karthaus M, Hecht JR, et al. Final analysis of the randomised PEAK trial: overall survival and tumour responses during firstline treatment with mFOLFOX6 plus either panitumumab or bevacizumab in patients with metastatic colorectal carcinoma. Int $J$ Colorectal Dis. 2017;32(8):1179-1190. doi:10.1007/s00384-0172800-1

27. Peeters M, Forget F, Karthaus M, et al. Exploratory pooled analysis evaluating the effect of sequence of biological therapies on overall survival in patients with RAS wild-type metastatic colorectal carcinoma. ESMO Open. 2018;3(2):e000297. doi:10.1136/esmoopen2017-000297

28. Carrato A, Abad A, Massuti B, et al. First-line panitumumab plus FOLFOX4 or FOLFIRI in colorectal cancer with multiple or unresectable liver metastases: a randomised, phase II trial (PLANET-TTD). Eur J Cancer. 2017;81:191-202. doi:10.1016/j. ejca.2017.04.024

29. Taieb J, Rivera F, Siena S, et al. Exploratory analyses assessing the impact of early tumour shrinkage and depth of response on survival outcomes in patients with RAS wild-type metastatic colorectal cancer receiving treatment in three randomised panitumumab trials. $J$ Cancer Res Clin Oncol. 2018;144(2):321-335. doi:10.1007/s00432017-2534-z

30. Goldberg RM, Montagut C, Wainberg ZA, et al. Optimising the use of cetuximab in the continuum of care for patients with metastatic colorectal cancer. ESMO Open. 2018;3(4):e000353. doi:10.1136/ esmoopen-2018-000353

31. Cremolini C, Rossini D, Dell'Aquila E, et al. Rechallenge for patients with RAS and BRAF wild-type metastatic colorectal cancer with acquired resistance to first-line cetuximab and irinotecan: a phase 2 single-arm clinical trial. JAMA Oncol. Epub 2018 Nov 21.

32. Mauri G, Pizzutilo EG, Amatu A, et al. Retreatment with anti-EGFR monoclonal antibodies in metastatic colorectal cancer: systematic review of different strategies. Cancer Treat Rev. 2019;73:41-53. doi:10.1016/j.ctrv.2018.12.006
33. Fornaro L, Lonardi S, Masi G, et al. FOLFOXIRI in combination with panitumumab as first-line treatment in quadruple wild-type (KRAS, NRAS, HRAS, BRAF) metastatic colorectal cancer patients: a phase II trial by the Gruppo Oncologico Nord Ovest (GONO). Ann Oncol. 2013;24(8):2062-2067. doi:10.1093/annonc/mdt165

34. Bendell JC, Zakari A, Peyton JD, et al. A phase II study of FOLFOXIRI plus panitumumab followed by evaluation for resection in patients with metastatic KRAS wild-type colorectal cancer with liver metastases only. Oncologist. 2016;21(3):279-280. doi:10.1634/ theoncologist.2015-0439

35. Geissler M, Klingler T, Martens UM, et al. 453PD1st-line mFOLFOXIRI + panitumumab vs FOLFOXIRI treatment of RAS wt mCRC: a randomized phase II VOLFI trial of the AIO (KRK0109). Ann Oncol. 2018;29(suppl_8). doi:10.1093/annonc/mdx807

36. Modest DP, Rivera F, Bachet JB, et al. Panitumumab-based maintenance after oxaliplatin discontinuation in metastatic colorectal cancer: a retrospective analysis of two randomised trials. Int J Cancer. 2019. doi:10.1002/ijc. 32110

37. Pietrantonio F, Morano F, Corallo S, et al. First-line FOLFOX plus panitumumab (Pan) followed by 5FU/LV plus pan or single-agent pan as maintenance therapy in patients with RAS wild-type metastatic colorectal cancer (mCRC): the VALENTINO study. J Clin Oncol. 2018;36(15_suppl):3505. doi:10.1200/JCO.2018.36.15_suppl.3505

38. Nakamura M, Munemoto Y, Takahashi M, et al. SAPPHIRE: a randomized phase II study of mFOLFOX6+ panitumumab versus 5FU/LV + panitumumab after 6 cycles of frontline mFOLFOX6+ panitumumab in patients with colorectal cancer. $J$ Clin Oncol. 2018;36(4_suppl):729. doi:10.1200/JCO.2018.36.4_suppl.729

39. Peeters M. Outcome according to Left Vs. Right Side in the Panitumumab Studies. Presented At: ESMO 2016 Congress, Special Session. Copenhagen, Denmark; October 7-11, 2016.

40. Boeckx N, Koukakis R, de Beeck KO, et al. Effect of primary tumor location on second- or later-line treatment outcomes in patients with RAS wild-type metastatic colorectal cancer and all treatment lines in patients with RAS mutations in four randomized panitumumab studies. Clin Colorectal Cancer. 2018;17(3):170-178.e173. doi:10.1016/ j.clcc.2018.03.005

41. Tejpar S, Stintzing S, Ciardiello F, et al. Prognostic and predictive relevance of primary tumor location in patients with RAS wild-type metastatic colorectal cancer: retrospective analyses of the CRYSTAL and FIRE-3 trials. JAMA Oncol. 2017;3(2):194-201. doi:10.1001/ jamaoncol.2016.3797

42. Peeters M, Price T, Taieb J, et al. Relationships between tumour response and primary tumour location, and predictors of long-term survival, in patients with RAS wild-type metastatic colorectal cancer receiving first-line panitumumab therapy: retrospective analyses of the PRIME and PEAK clinical trials. Br J Cancer. 2018;119(3):303312. doi:10.1038/s41416-018-0165-z

43. Holch JW, Ricard I, Stintzing S, Modest DP, Heinemann V. The relevance of primary tumour location in patients with metastatic colorectal cancer: a meta-analysis of first-line clinical trials. Eur $J$ Cancer. 2017;70:87-98. doi:10.1016/j.ejca.2016.10.007

44. Arnold D, Lueza B, Douillard JY, et al. Prognostic and predictive value of primary tumour side in patients with RAS wild-type metastatic colorectal cancer treated with chemotherapy and EGFR directed antibodies in six randomised trials. Ann Oncol. 2017. doi:10.1093/annonc/mdx 175

45. Stintzing S, Tejpar S, Gibbs P, Thiebach L, Lenz HJ. Understanding the role of primary tumour localisation in colorectal cancer treatment and outcomes. Eur $J$ Cancer. 2017;84:69-80. doi:10.1016/j. ejca.2017.07.016

46. Wagner LI, Lacouture ME. Dermatologic toxicities associated with EGFR inhibitors: the clinical psychologist's perspective. Impact on health-related quality of life and implications for clinical management of psychological sequelae. Oncology (Williston Park). 2007;21 (11 Suppl 5):34-36. 
47. Kohne CH, Hofheinz R, Mineur L, et al. First-line panitumumab plus irinotecan/5-fluorouracil/leucovorin treatment in patients with metastatic colorectal cancer. J Cancer Res Clin Oncol. 2012;138(1):6572. doi:10.1007/s00432-011-1061-6

48. Thaler J, Karthaus M, Mineur L, et al. Skin toxicity and quality of life in patients with metastatic colorectal cancer during first-line panitumumab plus FOLFIRI treatment in a single-arm phase II study. BMC Cancer. 2012;12:438. doi:10.1186/1471-2407-12-438

49. Siena S, Tabernero J, Bodoky G, et al. Quality of life during first-line FOLFOX4 \pm panitumumab in RAS wild-type metastatic colorectal carcinoma: results from a randomised controlled trial. ESMO Open. 2016;1(2):e000041. doi:10.1136/esmoopen-2016-000041

50. Bennett L, Zhao Z, Barber B, et al. Health-related quality of life in patients with metastatic colorectal cancer treated with panitumumab in first- or second-line treatment. Br J Cancer. 2011;105(10):14951502. doi:10.1038/bjc.2011.409

51. Odom D, Barber B, Bennett L, et al. Health-related quality of life and colorectal cancer-specific symptoms in patients with chemotherapyrefractory metastatic disease treated with panitumumab. Int $J$ Colorectal Dis. 2011;26(2):173-181. doi:10.1007/s00384-010-1112-5

52. Vectibix. INN-panitumumab. Available from: https://www.ema. europa.eu/en/documents/product-information/vectibix-epar-productinformation_en.pdf Accessed March 31, 2019.

53. Mitchell EP, Piperdi B, Lacouture ME, et al. The efficacy and safety of panitumumab administered concomitantly with FOLFIRI or Irinotecan in second-line therapy for metastatic colorectal cancer: the secondary analysis from STEPP (Skin Toxicity Evaluation Protocol With Panitumumab) by KRAS status. Clin Colorectal Cancer. 2011;10(4):333-339. doi:10.1016/j.clcc.2011.06.004

54. Lacouture ME, Mitchell EP, Piperdi B, et al. Skin toxicity evaluation protocol with panitumumab (STEPP), a phase II, open-label, randomized trial evaluating the impact of a pre-emptive skin treatment regimen on skin toxicities and quality of life in patients with metastatic colorectal cancer. J Clin Oncol. 2010;28(8):1351-1357. doi:10.1200/JCO.2008.21.7828

55. Peeters M, Siena S, Van Cutsem E, et al. Association of progressionfree survival, overall survival, and patient-reported outcomes by skin toxicity and KRAS status in patients receiving panitumumab monotherapy. Cancer. 2009;115(7):1544-1554. doi:10.1002/cncr.24088

56. Lacouture ME, Anadkat M, Jatoi A, Garawin T, Bohac C, Mitchell E. Dermatologic toxicity occurring during anti-EGFR monoclonal inhibitor therapy in patients with metastatic colorectal cancer: a systematic review. Clin Colorectal Cancer. 2018;17(2):85-96. doi:10.1016/j. clcc.2017.12.004

57. Kobayashi Y, Komatsu Y, Yuki S, et al. Randomized controlled trial on the skin toxicity of panitumumab in Japanese patients with metastatic colorectal cancer: HGCSG1001 study; J-STEPP. Future Oncol. 2015;11(4):617-627. doi:10.2217/fon.14.251

58. Fakih M, Vincent M. Adverse events associated with anti-EGFR therapies for the treatment of metastatic colorectal cancer. Curr Oncol. 2010;17(Suppl 1):S18-S30. doi:10.3747/co.v17is1.615

59. Costa A, Tejpar S, Prenen H, Van Cutsem E. Hypomagnesaemia and targeted anti-epidermal growth factor receptor (EGFR) agents. Target Oncol. 2011;6(4):227-233. doi:10.1007/s11523011-0200-y

60. Vincenzi B, Galluzzo S, Santini D, et al. Early magnesium modifications as a surrogate marker of efficacy of cetuximab-based anticancer treatment in KRAS wild-type advanced colorectal cancer patients. Ann Oncol. 2011;22(5):1141-1146. doi:10.1093/annonc/ mdq550

61. Sastre J, Massuti B, Pulido G, et al. First-line single-agent panitumumab in frail elderly patients with wild-type KRAS metastatic colorectal cancer and poor prognostic factors: a phase II study of the Spanish cooperative group for the treatment of digestive tumours. Eur J Cancer. 2015;51(11):1371-1380. doi:10.1016/j. ejca.2015.04.013
62. Pietrantonio F, Cremolini C, Aprile G, et al. Single-agent panitumumab in frail elderly patients with advanced RAS and BRAF wild-type colorectal cancer: challenging drug label to light up new hope. Oncologist. 2015;20(11):1261-1265. doi:10.1634/theoncologist.2015-0171

63. Douillard J, Siena S, Peeters M, Koukakis R, Terwey J, Tabernero J. 547pimpact of baseline age on efficacy and safety of first-line panitumumab (PMAB) + folfox4 vs folfox4 treatment. Ann Oncol. 2014;25(suppl 4):iv187-iv187. doi:10.1093/annonc/mdu333.49

64. Asimakopoulou N, Souglakos J, Kentepozidis N, et al. Efficacy of panitumumab in older patients with metastatic colorectal cancer: a retrospective analysis using the database of the Hellenic Oncology Research Group (HORG). J Geriatr Oncol. 2019;10(1):143-148. doi:10.1016/j.jgo.2018.08.002

65. Bertotti A, Papp E, Jones S, et al. The genomic landscape of response to EGFR blockade in colorectal cancer. Nature. 2015;526(7572):263267. doi:10.1038/nature 14969

66. Bertotti A, Migliardi G, Galimi F, et al. A molecularly annotated platform of patient-derived xenografts ("xenopatients") identifies HER2 as an effective therapeutic target in cetuximab-resistant colorectal cancer. Cancer Discov. 2011;1(6):508-523. doi:10.1158/21598290.CD-11-0109

67. Sartore-Bianchi A, Trusolino L, Martino C, et al. Dual-targeted therapy with trastuzumab and lapatinib in treatment-refractory, KRAS codon 12/13 wild-type, HER2-positive metastatic colorectal cancer (HERACLES): a proof-of-concept, multicentre, open-label, phase 2 trial. Lancet Oncol. 2016;17(6):738-746. doi:10.1016/ S1470-2045(16)00150-9

68. Townsend A, Tebbutt N, Karapetis C, et al. Phase IB/II study of second-line therapy with Panitumumab, Irinotecan, and Everolimus (PIE) in KRAS Wild-Type Metastatic Colorectal Cancer. Clin Cancer Res. 2018;24(16):3838-3844. doi:10.1158/1078-0432.CCR-17-3590

69. Corcoran RB, Andre T, Atreya CE, et al. Combined BRAF, EGFR, and MEK inhibition in patients with BRAF(V600E)-mutant colorectal cancer. Cancer Discov. 2018;8(4):428-443. doi:10.1158/2159. 8290.CD-17-1226

70. Cremolini C, Morano F, Moretto M, et al. Dissecting primary resistance to anti-EGFRs in RAS and BRAF wt metastatic colorectal cancer (mCRC): a case-control study. J Clin Oncol. 2017;35(suppl; abstr 11508). doi:10.1200/JCO.2017.35.15_suppl.11508

71. Misale S, Di Nicolantonio F, Sartore-Bianchi A, Siena S, Bardelli A. Resistance to anti-EGFR therapy in colorectal cancer: from heterogeneity to convergent evolution. Cancer Discov. 2014;4(11):12691280. doi:10.1158/2159-8290.CD-14-0462

72. Bettegowda C, Sausen M, Leary RJ, et al. Detection of circulating tumor DNA in early- and late-stage human malignancies. Sci Transl Med. 2014;6(224):224ra224. doi:10.1126/scitranslmed.3007094

73. Siravegna G, Mussolin B, Buscarino M, et al. Clonal evolution and resistance to EGFR blockade in the blood of colorectal cancer patients. Nat Med. 2015;21(7):795-801. doi:10.1038/nm.3870

74. Morelli MP, Overman MJ, Dasari A, et al. Characterizing the patterns of clonal selection in circulating tumor DNA from patients with colorectal cancer refractory to anti-EGFR treatment. Ann Oncol. 2015;26(4):731-736. doi:10.1093/annonc/mdv005

75. Parseghian CM, Loree JM, Morris VK, et al. Anti-EGFR-resistant clones decay exponentially after progression: implications for anti-EGFR rechallenge. Ann Oncol. 2019;30(2):243-249. doi:10.1093/annonc/mdy509

76. Sartore-Bianchi A, Siena S, Bardelli A, et al. Dynamic molecular analysis and clinical correlates of tumor evolution within a phase II trial of panitumumab-based therapy in metastatic colorectal cancer. Ann Oncol. 2017;29(1):119-126.

77. Peeters M, Price T, Boedigheimer M, et al. Evaluation of emergent mutations in circulating cell-free DNA and clinical outcomes in patients with metastatic colorectal cancer treated with panitumumab in the ASPECCT study. Clin Cancer Res. 2019;25(4):1216-1225. doi:10.1158/1078-0432.CCR-18-2072 
78. Kim TW, Peeters M, Thomas A, et al. Impact of emergent circulating tumor DNA RAS mutation in panitumumab-treated chemoresistant metastatic colorectal cancer. Clin Cancer Res. 2018;24(22):56025609. doi:10.1158/1078-0432.CCR-17-3377

79. Santos C, Azuara D, Vieitez JM, et al. Phase II study of highsensitivity genotyping of KRAS, NRAS, BRAF and PIK3CA to ultra-select metastatic colorectal cancer patients for panitumumab plus FOLFIRI: the ULTRA trial. Ann Oncol. 2019;30(5):796-803. doi:10.1093/annonc/mdz082

80. Kim TW, Elme A, Kusic Z, et al. A phase 3 trial evaluating panitumumab plus best supportive care vs best supportive care in chemorefractory wild-type KRAS or RAS metastatic colorectal cancer. $\mathrm{Br} J$ Cancer. 2016;115(10):1206-1214. doi:10.1038/ bjc. 2016.309
81. Peeters M, Price TJ, Cervantes A, et al. Final results from a randomized phase 3 study of FOLFIRI $\{ \pm\}$ panitumumab for second-line treatment of metastatic colorectal cancer. Ann Oncol. 2014;25 (1):107-116. doi:10.1093/annonc/mdt523

82. Hecht JR, Cohn A, Dakhil S, et al. SPIRITT: a randomized, multicenter, phase II study of panitumumab with FOLFIRI and bevacizumab with FOLFIRI as second-line treatment in patients with unresectable wild type KRAS metastatic colorectal cancer. Clin Colorectal Cancer. 2015;14(2):72-80. doi:10.1016/j. clcc.2014.12.009

\section{Publish your work in this journal}

Cancer Management and Research is an international, peer-reviewed open access journal focusing on cancer research and the optimal use of preventative and integrated treatment interventions to achieve improved outcomes, enhanced survival and quality of life for the cancer patient.
The manuscript management system is completely online and includes a very quick and fair peer-review system, which is all easy to use. Visit http://www.dovepress.com/testimonials.php to read real quotes from published authors. 